\title{
Optimization analysis of integrated energy system based on wind power hydrogen production equipment
}

\author{
Fenyu Zeng, Kunpeng Chen
}

Abstract - The output of wind power is random, fluctuating, and anti-peak-modulating. A large number of wind farms have to be forced to abandon the wind, which has brought a lot of impact on the power grid system, making grid dispatching more and more difficult, and the power supply Small impact. The method of producing hydrogen by electrolyzing water converts excess wind energy into hydrogen energy and improves various energy utilization efficiency in the integrated energy system. The comprehensive energy system containing hydrogen production equipment can meet the needs of electricity, heat and cooling loads in the area, reducing the overall operating cost. Experiments prove that electrolytic hydrogen production improves the digestion capacity of wind power.

Index Terms-fuel cells, integrated energy systems, multi-energy complementarity, wind power dissipation.

\section{INTRODUCTION}

The scale of China's wind power installations continues to expand. According to statistics from the National Energy Administration, in 2019, the country's new wind power installed capacity will be 25.74 million kilowatts. At the end of the year, the cumulative installed capacity of wind power nationwide was 210 million kilowatts, of which cumulative installed capacity of onshore wind power was 204 million kilowatts and cumulative installed capacity of offshore wind power was 5.93 million kilowatts. In 2019, wind power generation amounted to 405.7 billion $\mathrm{kWh}$, exceeding 400 billion $\mathrm{kWh}$ for the first time, accounting for $5.5 \%$ of the total power generation. Due to the randomness, fluctuation, and anti-peak regulation of wind power output, the problem of large-scale wind power grid connection is becoming increasingly apparent, and many wind farms have to be forced to abandon wind.

Fenyu Zeng, Professor of School of Economics and Management of Shanghai University of Electric Power, China.

Kunpeng Chen, Postgraduate of School of Economics and Management of Shanghai University of Electric Power, China.
The big shock has made the power grid dispatching more and more difficult, which has a significant impact on power supply. In order to solve these problems in the development of wind power, this paper studies a comprehensive energy system with wind power to produce hydrogen as the core. Through energy conversion, it is verified to promote the development of renewable energy and improve energy efficiency.

The integrated energy system combines various energy forms such as electricity, heat, gas, etc. to uniformly coordinate and optimize various types of energy in the region, that is, to increase the space-time coupling mechanism and complementary substitution between different links in production, transmission and distribution, consumption, and storage. Increasing the proportion of energy supply and utilization of renewable energy. Under the framework of the integrated energy system, the technology of converting idle wind power into hydrogen is used to better achieve energy storage and clean utilization, which is one of the important solutions to improve wind power consumption.

\section{LITERATURE REVIEW}

The volatility and uncertainty of renewable energy have caused great difficulties in practical use. [1] introduced size optimization methodologies and evaluated the economics and reliability of combined solar and wind energy systems. [2] introduced the system optimization and energy management strategies of independent photovoltaic and wind energy systems integrated with fuel cells, and optimized and formed a cost-effective system. Benefit system. [3] proposed an optimization method for renewable energy systems to meet the load with the minimum total cost, indicating that wind turbines are an indispensable power component in renewable energy systems. In order to use renewable energy efficiently, hydrogen storage has become a research direction. By using a novel strategy of genetic algorithm, [4] optimized a renewable energy system with a 
Optimization analysis of integrated energy system based on wind power hydrogen production equipment

hydrogen storage function to determine the most economical This method solves the energy shortage problem and illustrates its application in photovoltaic-diesel-battery-hydrogen systems. [5] introduced the application of electrolytic hydrogen in an independent renewable energy system. The stored hydrogen was fed back to the fuel cell to generate electricity. Power regulation proved that the independent renewable energy system containing hydrogen was safe and reliable. [6] designed and optimized the renewable energy and hydrogen storage power generation systems, and used stochastic annealing optimization algorithms to consider the uncertainty of different types of power sources and make multiple subsystems work together. The results show that the system design performance is stable and reliable. [7] discussed adding storage systems to ensure the continuity of power supply to the load, detailed analysis of possible configurations in hybrid power systems, and proving that the effective use of excess energy can reduce the energy costs of renewable energy systems.

[8] proposed a novel energy management strategy to control the micro-grid containing hydrogen production and storage systems to maximize the benefits of using renewable resources by minimizing the total cost. After evaluating the uncertainty of renewable energy using a random method, the experimental results show that the cost has been reduced by about $15 \%$, and the average energy storage efficiency has improved. [9] reviewed and analyzed different energy management strategies for hybrid renewable energy systems containing hydrogen reserves. By storing hydrogen energy, synergistic effects of renewable energy sources such as photovoltaics and wind energy were used to improve the efficiency of energy use and make renewable energy systems. Maintain optimal performance. For the independent hybrid power system based on photovoltaic (PV) solar panels, hydrogen subsystems and batteries, [10] proposed a size adjustment method and different control strategies suitable for energy management. Through MATLAB-Simulink simulation experiments, technical optimization and cost analysis of the hybrid system were performed. The results prove that the proposed controlled hybrid system can provide the energy required by the load while maintaining a certain energy reserve in the storage source. [11] performed mathematical modeling through
Simorer, a multi-domain simulation platform, and established a photovoltaic fuel cell hybrid system. The excess power from the PV generator was used for water electrolysis to generate hydrogen. The hybrid power system successfully tracked the daily use of typical households. The electrical situation validates the effectiveness of the proposed management method for the operation of an independent hybrid power system.

In his research, [12] combined wind energy production and biomass gasification systems, and studied the technical and economic feasibility of large hydrogen-based compensation systems. The combination of the two systems works synergistically to improve the end result. [13] considered actual wind speed data from wind farms, used renewable primary energy to produce hydrogen, and monitored changes in cell stack voltage, efficiency, and temperature, as well as the purity of hydrogen and oxygen produced. The results show that the electrolytic cell has reliable performance, high efficiency, satisfactory gas purity, and fast dynamic response to changing conditions. [14] studied the integrated system that converts wind power surplus electricity into hydrogen energy, and considered the constraints of hydrogen energy storage, hydrogen sales, electric power systems, and district heating systems through modeling. Simulation results show that the system can improve wind power Integration and reduce system operating costs. In order to improve the capacity of wind power, [15] proposed a method of consuming waste wind energy in a hydrogen production system, and used the interval optimization theory to determine the optimal capacity allocation area of the hydrogen production system. More economical.

This paper considers the conversion of various energies in an integrated energy system, and takes different forms of idle wind power as research content, and proposes a system optimization model for the total cost of an integrated energy supplier using a wind power hydrogen production unit. Set up an example to meet the requirements of electricity, heat, and cold load in the system, make full use of idle wind power, and verify the feasibility of the system through example analysis. The discussion results prove that the integrated energy system containing hydrogen production equipment makes better use of energy. Increased wind 
power consumption, improved the overall efficiency of the system, and achieved efficient use of clean energy.

\section{DESCRIPTION OF INTEGRATED ENERGY SYSTEM}

\section{A. Principle of electric hydrogen conversion}

The wind-hydrogen coupling system for hydrogen production mainly includes wind turbines, electrolyzed water devices, hydrogen energy storage systems, and fuel cell devices. Through the chemical reaction of the electrolytic device, the mutual conversion between hydrogen energy and electric energy can be realized: the water electrolysis device consumes electric energy and generates hydrogen to realize the conversion of electric energy to hydrogen energy; meanwhile, the fuel cell can use hydrogen to generate electric energy and realize the conversion from hydrogen energy to electric energy Conversion. The hydrogen production system consists of multiple electrolytic cells. The electrolytic cell is a device that electrolyzes water into $\mathrm{H}_{2}$ and $\mathrm{O}_{2}$ by applying direct current to its electrodes. The expression of its chemical reaction is

$$
2 \mathrm{H}_{2} \mathrm{O} \boxminus \text { eqeatrify } 2 \mathrm{H}_{2} \uparrow+\mathrm{O}_{2} \uparrow
$$

After the alkaline electrolytic cell is used to electrolyze the solution, the generated hydrogen can be stored or transferred using a hydrogen storage device. On the one hand, it can be used to supply fuel cells when the power system load increases to meet the power load demand; on the other hand, it can be used as industrial supplies. In the integrated energy system, the hydrogen energy is converted into electrical energy through the fuel cell, and the heat released during the hydrogen combustion process can be supplied to the heat load of the system.

In practical applications, the hydrogen production process is usually combined with the consumption of renewable energy. When the power load is low, the surplus renewable energy is converted into hydrogen energy storage to meet.

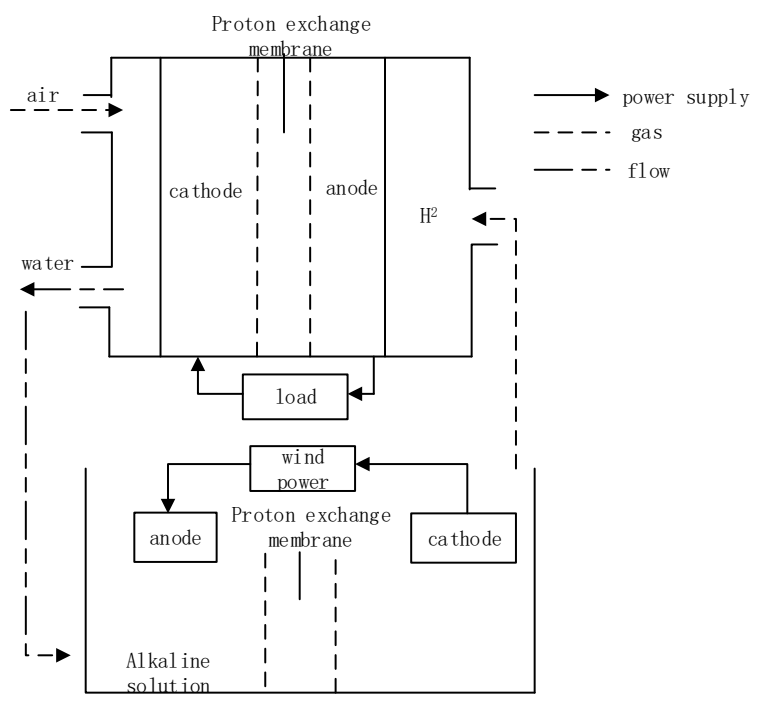

Fig.1 Schematic of electro-hydrogen conversion

\section{B. Comprehensive energy system containing electric hydrogen production equipment}

the needs of industrial hydrogen (such as medical, steelmaking, aviation, and Green energy vehicles, etc.), and convert hydrogen energy into electricity to meet load demand at the peak of power load, while also increasing the consumption of renewable energy. In this paper, considering the wind power hydrogen production process, a comprehensive energy system with an electric hydrogen production device as shown in Fig. 2 is constructed, which meets the electrical load, heat load, and cold demand while promoting the consumption of renewable energy. Among them, the wind power hydrogen-fuel cell power generation system and thermal system provide the necessary conditions for the conversion of electrical energy, hydrogen energy and thermal energy.

In this article, part of the system's electrical load supply comes from the external power grid, and the other part comes from the system's internal power sources, including photovoltaic power, wind turbines, gas turbine units, and electrical energy storage equipment. Distributing renewable energy output within the digestion system. The heat load preferentially uses the heat recovery of gas turbines and fuel cells as the heating source, and the shortfall is provided by gas boilers and thermal energy storage equipment. The supply of cooling load is jointly supplied by electric refrigeration and absorption refrigeration to achieve complementarity between multiple energy sources. 


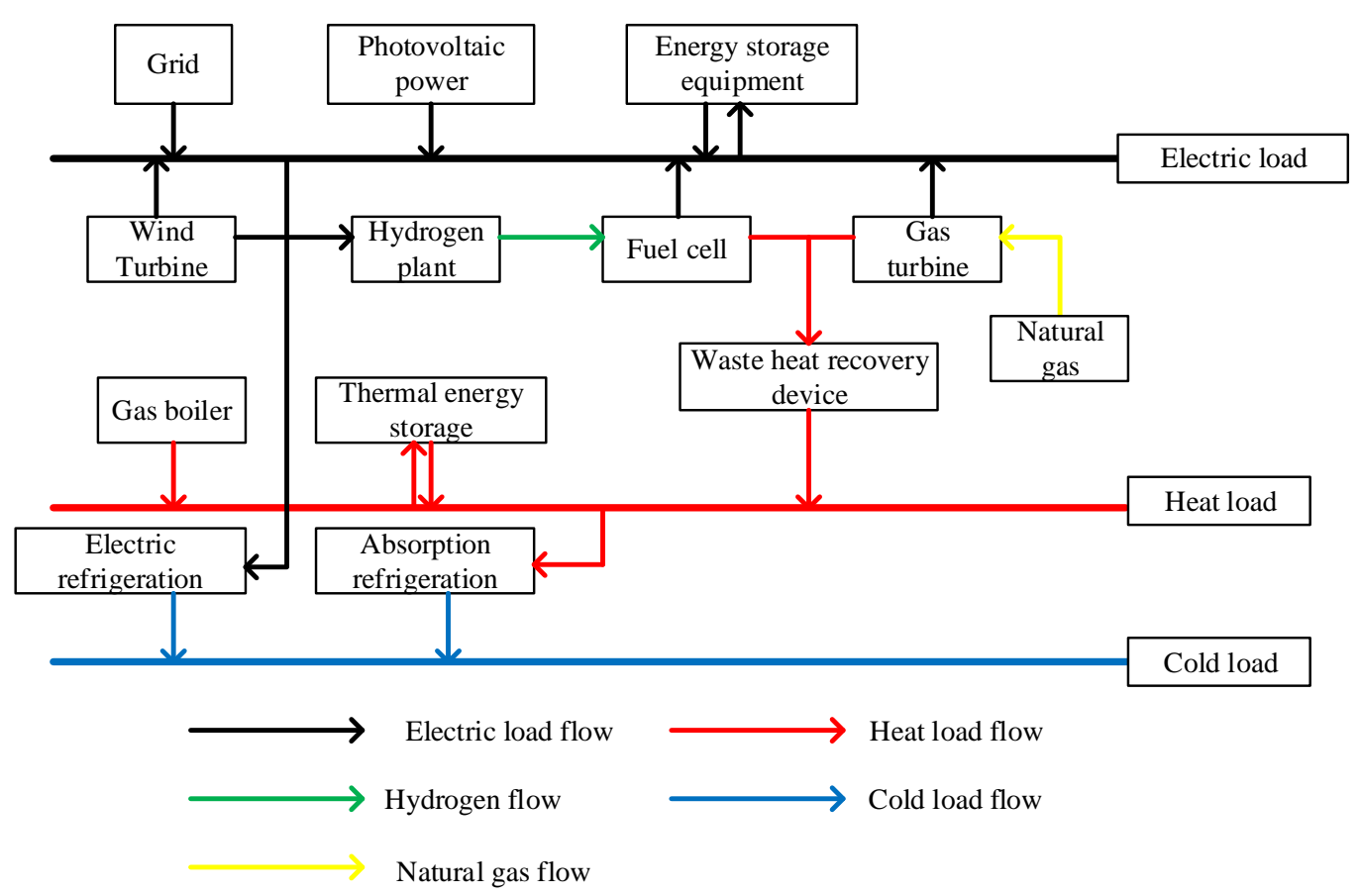

Fig.2 Integrated energy system with wind power hydrogen production unit

Wind power hydrogen-fuel cell devices in integrated energy systems include wind turbines, water electrolysis devices, fuel cell devices, hydrogen storage devices, compression devices, rectifiers and inverter devices, and control systems. The electrical energy generated by the wind turbine flows into the power grid through the transformer. After meeting the local electrical load demand, the surplus wind power can input DC power to the water electrolysis device through the rectifier to electrolyze the water. Hydrogen generated by electrolyzed water enters a hydrogen-cooled separator through a hydrogen outlet pipe for cooling, and is discharged after separation to obtain high-purity hydrogen. The obtained hydrogen is concentratedly injected into hydrogen storage equipment through pipelines and compression devices, part of which is used for industry and transportation, and part of which is used for fuel cell power generation. The control system of the distributed energy supply device for wind power hydrogen-fuel cell mainly includes the following functions: (1) Power balance control. According to the requirements of electric energy dispatching, hydrogen production and fuel cell power generation systems, wind power control is performed to meet the power balance of the power system; (2) Wind power voltage control. Use controllable equipment such as reactive power compensation equipment to achieve wind power output voltage stability; (3) control of wind power hydrogen production and fuel cell power generation systems. Control the operation of hydrogen production from electrolyzed water and fuel cell power generation devices based on grid load demand and wind power generation.

\section{Energy conversion mode of integrated energy system}

The integrated energy system of the hydrogen-producing device with electricity in this paper mainly has the requirements of electricity, heat and cold load, there are multiple coupling relationships between different energy forms, and they are transformed into each other in the integrated energy system. Starting from the bottom of the power load, this paper focuses on whether there are idle wind power and the different ways to deal with the idle wind power. Four main operation modes are given. The specific operation is shown in Table 1:

Table.1 Four operation modes

\begin{tabular}{ccc}
\hline & Electric energy storage & Electric Hydrogen \\
\hline Scenario 1 & - & - \\
Scenario 2 & + & - \\
Scenario 3 & - & + \\
Scenario 4 & + & + \\
\hline
\end{tabular}

1) Scenario 1: Abandon the wind directly. When the load demand in the system is low, the wind turbine will produce excess power, choose idle wind power, and do not use electricity storage and electricity to produce hydrogen. At this time, the electrical load in the system is provided by the external power grid, wind turbine, gas turbine, and photovoltaic power.

2) Scenario 2: Use energy storage equipment to store the 
remaining wind power for backup when the system electrical load is at a trough. When the electrical load demand in the system is large, the energy storage equipment participates in power supply.

3) Scenario 3: Start hydrogen plant. In this scenario, the electrolytic device starts working and stores hydrogen. When the electrical load demand in the system is large, hydrogen is supplied to the fuel cell. At the same time, the fuel cell and gas turbine can also provide a certain amount of thermal load.

4) Scenario 4: Simultaneously start the electric energy storage device and the electric hydrogen production device. At this time, the electric energy storage and the electric hydrogen production device are mutually reserve, and both participate in the wind power dissipation during the load valley period.

\section{OPTIMIZED MODEL OF INTEGRATED ENERGY SYSTEM}

\section{A. Objective function}

In order to improve the utilization level of wind power, priority is given here to the consumption of idle wind power. With the total operating cost of the integrated energy system as the research target, a comprehensive energy optimization system model with wind power installations is constructed. The objective function is

$$
\min =C_{p}+C_{o p}
$$

$C_{p}$ is the purchase cost of the system; $C_{o p}$ is the total operation and maintenance cost of the system.

The purchasing cost of the system is

$$
C_{\mathrm{p}}=\sum_{t=1}^{T}\left(f_{\text {gas }, t} \lambda_{\text {gas }}+P_{\text {grid }} \lambda_{e, t}\right)
$$

$f_{g a s, t}$ is the air intake of the gas turbine during the period $\mathrm{t} ; \lambda_{\text {gas }}$ is the price of natural gas; $P_{\text {grid }}$ is the power exchange between the integrated energy system and the grid; $\lambda_{e, t}$ is the price of electricity during the period $\mathrm{t}$.

The total operation and maintenance cost of the system can be expressed as

$$
C_{\text {op }}=\sum_{t=1}^{T} \sum_{i=1}^{I} c_{i} P_{j, t}
$$

$c_{i}$ is the operating hours of each device; $P_{j, t}$ is the unit operation and maintenance cost of each device during $t$ period.

\section{B. Constraints}

a) Electric power balance constraints

The electric power balance in the integrated energy system is

$$
\begin{aligned}
& P_{g r i d, t}+P_{G T, t}+P_{W T, t}+P_{P V, t}+P_{F C, t}+P_{E S, t}^{d i s} \\
& =L_{e, t}+P_{E S, t}^{c h a r}+P_{E C, t}+P_{E B, t}
\end{aligned}
$$

$P_{g r i d, t}$ is the exchange power of the integrated energy system and grid at time t; $P_{G T, t}$ is the power generation of the gas turbine at time $\mathrm{t} ; P_{W T, t}$ is the output of the wind turbine at time $\mathrm{t} ; \quad P_{P V, t}$ is the output of photovoltaic power at time $\mathrm{t} ; P_{F C, t}$ is the output of the fuel cell at time $\mathrm{t} ; P_{E S, t}^{d i s}$ is the power storage equipment at time $\mathrm{t} ; L_{e, t}$ is the electric load at time $\mathrm{t} ; P_{E S, t}^{\text {char }}$ is the charging power of the electric energy storage equipment at time t; $P_{E C, t}$ is the power absorbed by the electric refrigeration equipment at time t; $P_{E B, t}$ is the power of the electric boiler at time t.

\section{b) Fuel cell device constraints}

In the wind power hydrogen-fuel cell device, the electrolytic cell, fuel cell, and hydrogen storage device are considered as a whole. During the energy storage conversion process, taking into account the energy consumption of each link, the comprehensive equivalent electric power is used to represent each physical quantity.

The equivalent electric power for hydrogen production in the hydrogen production period of the electrolytic cell is

$$
P_{\mathrm{H} 2, t}=\alpha_{\mathrm{E} 2 \mathrm{H}} P_{\mathrm{E} 2 \mathrm{H}, t}
$$

The power generated by the proton membrane fuel cell is

$$
P_{\mathrm{H} 2 \mathrm{P}, t}=\beta_{\mathrm{H} 2 \mathrm{P}} P_{\mathrm{H}-\mathrm{FC}, t}
$$

The equivalent state of charge of the hydrogen storage capacity of the hydrogen storage tank in the $\mathrm{t}$-th period is

$$
E_{\mathrm{H} 2, t}=E_{\mathrm{H} 2, t-1}-\left(P_{\mathrm{H}-\mathrm{FC}, t}+P_{\mathrm{SH}, t}-P_{\mathrm{H} 2 \mathrm{P}, t}\right) \eta_{\mathrm{H} 2} \Delta t
$$


$P_{\mathrm{E} 2 \mathrm{H}, t}$ and $P_{\mathrm{H} 2 \mathrm{P}, t}$ are the power consumption of electrolysis and the equivalent electric power of hydrogen consumption; $\alpha_{\mathrm{E} 2 \mathrm{H}}$ and $\beta_{\mathrm{H} 2 \mathrm{P}}$ are the comprehensive conversion efficiency of the electrolytic cell and the fuel cell respectively; $E_{\mathrm{H} 2, t}, P_{\mathrm{SH}, t}$, and are the remaining hydrogen storage equivalent power and hydrogen load at time $\mathrm{t} ; \eta_{\mathrm{H} 2}$ is hydrogen energy consumption, that is, the power consumption of generating standard cubic meters of hydrogen per hour, the unit is $\mathrm{kW} / \mathrm{Nm}^{3}$.

The operation of electrolytic devices and fuel cells is subject to the following constraints

$$
\left\{\begin{array}{l}
P_{e}^{\min } m_{e, t} n_{e, t} \leq P_{e, t} \leq P_{e}^{\max } m_{e, t} n_{e, t} \\
P_{F C}^{\min } m_{F C, t} n_{F C, t} \leq P_{F C, t} \leq P_{F C}^{\max } m_{F C, t} n_{F C, t} \\
m_{e, t} n_{e, t}+m_{F C, t} n_{F C, t} \leq 1
\end{array}\right.
$$

$m_{e, t}$ and $m_{F C, t}$ are the initialization state parameters of the water electrolysis device and the fuel cell device. 0 means that the water electrolysis device is in a forced shutdown state, and 1 means that it is in an adjustable working state. The initialization parameters are assigned during initialization. $n_{e, t}$ and $n_{F C, t}$ are the water electrolysis device and fuel. The running state of the battery is $0-1$. 0 means that the water electrolysis device is in a shutdown state, and 1 means it is in a working state. This formula indicates that the water electrolysis device and the fuel cell cannot run at the same time. $P_{e}^{\max }$ and $P_{F C}^{\max }$ are the maximum power consumed by the electrolytic device and the minimum output power of the fuel cell; $P_{e}^{\min }$ and $P_{F C}^{\min }$ are the minimum power consumed by the electrolytic device and the minimum output power of the fuel cell.

\section{c) Thermal system constraints}

The thermal balance in the integrated energy system is

$$
\begin{aligned}
& H_{G T, t}+H_{F C, t}+\eta_{E B} P_{E B, t}+\eta_{G B} P_{G B, t}+H_{H S, t}^{d i s} \\
& =L_{h, t}+H_{H S, t}^{\text {char }}
\end{aligned}
$$

$H_{G T, t}$ is the heat generated by the gas turbine at time $\mathrm{t}$;

$H_{F C, t}$ is the thermal power released by the fuel cell at time t;

$\eta_{E B}$ is the heat production efficiency of the electric boiler; $\eta_{G B}$ is the heat production efficiency of the gas boiler;
$H_{H S, t}^{d i s}$ is the energy released by the thermal energy storage equipment at time t; $L_{h, t}$ is the heat load at time $\mathrm{t} ; H_{H S, t}^{\text {char }}$ is the energy absorbed by the thermal energy storage device at time t.

The cooling balance in the integrated energy system is

$$
\eta_{E C} P_{E C, t}+\eta_{A C} P_{A C, t}=L_{C, t}
$$

$\eta_{E C}$ is the refrigeration efficiency of the electric refrigeration equipment; $\eta_{A C}$ is the refrigeration efficiency of the absorption refrigeration equipment; $P_{A C, t}$ is the power absorbed by the absorption refrigeration equipment at time $\mathrm{t} ; L_{C, t}$ is the cooling load at time t.

The operating characteristic model of the gas turbine is

$$
\begin{aligned}
& \eta_{G T, E}(t)=K_{\eta 3}\left(\frac{P_{G T}(t)}{P_{G T N}}\right)^{3}+K_{\eta 2}\left(\frac{P_{G T}(t)}{P_{G T N}}\right)^{2} \\
& +K_{\eta 1}\left(\frac{P_{G T}(t)}{P_{G T N}}\right)+K_{\eta 0}
\end{aligned}
$$

$$
v_{G T}(t)=\delta_{G T}\left[\begin{array}{l}
K_{v 3}\left(\frac{P_{G T}(t)}{P_{G T N}}\right)^{3} \\
+K_{v 2}\left(\frac{P_{G T}(t)}{P_{G T N}}\right)^{2}+K_{v 1}\left(\frac{P_{G T}(t)}{P_{G T N}}\right)+K_{v 0}
\end{array}\right]
$$

$\eta_{G T, E}$ is the power generation efficiency of the gas turbine; $K_{\eta i}$ is the fitting parameter of the power generation efficiency characteristic curve; $P_{G T}(t)$ and $P_{G T N}$ are the output and rated output of the gas turbine respectively; $v_{G T}(t)$ is the gas turbine gas consumption rate; $\delta_{G T}$ is the start and stop status of the gas turbine. The outage is 0 and the operation is $1 ; K_{v i}$ is the fitting parameter of the air consumption characteristic curve.

The following are the constraints of the thermoelectric ratio of the fuel cell and gas turbine units, and the upper and lower limits of the gas group output

$$
\left\{\begin{array}{l}
H_{\mathrm{FC}, t}=K_{H} P_{F C, t} \\
H_{G T, t}=K_{G T} P_{G T, t} \\
P_{G T}^{\min } \leq P_{G T, t} \leq P_{G T}^{\max }
\end{array}\right.
$$

$K_{H}$ is the thermoelectric ratio; $K_{G T}$ is the thermoelectric 
ratio of the Gas turbine unit. $P_{G T}^{\min }, P_{G T}^{\max }$ are the minimum and maximum output power of the gas turbine.

\section{d) Storage System Constraints}

For electrical energy storage, the following energy constraints must be met

$$
\left\{\begin{array}{l}
K(T+1)=K(T)\left(1-\sigma_{E S}\right) \\
-\left(\eta_{E S, \text { char }} I_{E S, \text { char }} P_{E S, t}^{\text {char }}+\frac{1}{\eta_{E S, d i s}} I_{E S, \text { dis }} P_{E S, t}\right) \frac{\Delta t}{Q_{E S-\text { cap }}} \\
I_{E S, \text { char }}+I_{E S, \text { dis }} \in(0,1) \\
K_{\min } \leq K(T+1) \leq K_{\max }
\end{array}\right.
$$

$K(T+1)$ and $K(T)$ are the state of charge of the electric energy storage equipment at time points $T+1$ and $T$ (before and after charging and discharging); $K_{\min }$ and $K_{\max }$ are the lower and upper limits of the state of charge of the electric energy storage equipment; $\sigma_{E S}$ is the self-discharge rate; $\eta_{E S, \text { char }}$ and $\eta_{E S \text {,dis }}$ are charge and discharge efficiency respectively; $I_{E S, c h a r}$ and $I_{E S, \text { dis }}$ are charge and discharge state variables of electric energy storage equipment, respectively. $Q_{E S-c a p}$ is the capacity of the electric energy storage device.

Charge and discharge power constraints of electric energy storage equipment

$$
\left\{\begin{array}{l}
I_{E S, \text { char }} P_{E S_{\min }}^{\text {char }}+I_{E S, \text { dis }} P_{E S_{\min }} \leq P_{E S . c h a r / E S . d i s} \\
P_{E S . \text { char } / E S . \text { dis }} \leq I_{E S, \text { char }} P_{E S_{\max }}^{\text {char }}+I_{E S, \text { dis }} P_{E S_{\max }}
\end{array}\right.
$$

$P_{E S_{\min }}^{\text {char }}$ and $P_{E S_{\min }}$ are the minimum charge and discharge power of electric energy storage equipment; $P_{E S_{\max }^{c h a r}}$ and $P_{E S_{\max }}$ are the maximum charge and discharge power of electric energy storage equipment. $P_{E S \text {.charlES.dis }}$ is the charge and discharge power of electric energy storage equipment.

The energy constraint in thermal energy storage equipment is

$$
\left\{\begin{array}{l}
E_{H S}(T+1)=E_{H S}(T)\left(1-\sigma_{H S}\right) \\
-\left(\eta_{H S, \text { char }} I_{H S, \text { char }}(T) H_{H S}^{\text {char }}+\frac{1}{\eta_{H S, d i s}} I_{H S, d i s}(T) H_{H S}^{\text {dis }}\right) \Delta t \\
I_{H S, \text { char }}(T)+I_{H S, d i s}(T) \in(0,1) \\
E_{\mathrm{HS}_{\min }} \leq E_{H S}(T+1) \leq E_{\mathrm{HS}_{\max }}
\end{array}\right.
$$

$E_{H S}(T+1)$ and $E_{H S}(T)$ are the capacity of the thermal energy storage equipment at time points $T+1$ and $T$; $E_{\mathrm{HS}_{\min }}$ and $E_{\mathrm{HS}_{\max }}$ are the lower and upper limits of the thermal energy storage equipment capacity; $\sigma_{H S}$ is the heat dissipation rate of the thermal energy storage equipment; $\eta_{H S, \text { char }}$ and $\eta_{H S, \text { dis }}$ are charging Exothermic efficiency; $I_{H S, \text { char }}$ and $I_{H S, d i s}$ are the charge and exothermic state variables of the thermal energy storage equipment, respectively.

Thermal energy storage equipment charge and discharge power constraints are

$$
\left\{\begin{array}{l}
I_{H S, \text { char }} H_{H S \text { min }}^{\text {char }}+I_{H S, d i s} H_{H S \text { min }}^{d i s} \leq H_{H S, \text { char } / H S, d i s} \\
H_{H S, \text { char } / H S, \text { dis }} \leq I_{H S, \text { char }} H_{H S \text { max }}^{\text {char }}+I_{H S, \text { dis }} H_{H S \text { max }}^{d i s}
\end{array}\right.
$$

$H_{H S \text { min }}^{\text {char }}$ and $H_{H S \text { min }}^{\text {dis }}$ are the minimum charging and discharging power of thermal energy storage equipment; $H_{H S \max }^{\text {char }}$ and $H_{H S \text { max }}^{\text {dis }}$ are the maximum charging and discharging power of thermal energy storage equipment; $H_{H S, \text { char } / H S \text {,dis }}$ is the charging and discharging power of thermal energy storage equipment.

\section{SIMULATION AND ANALYSIS}

\section{A. Basic data}

This paper selects a comprehensive energy system in a park in Shanghai for example analysis. The system includes wind turbines, photovoltaic generators, electric hydrogen generators, fuel cell devices, energy storage equipment, hydrogen storage equipment, gas boilers, absorption refrigeration units, Electric refrigeration unit. Table 2-4 shows the safety operation limits and unit operation and maintenance costs of energy supply and conversion equipment in the system. Among them, the charge and discharge efficiency of energy storage equipment are 0.95 
and 0.87 respectively; the fuel coefficient of gas turbines are 2.035 yuan and $60 \times 10^{-3}$ yuan $/ \mathrm{kW} \cdot \mathrm{h}, 44 \times 10^{-6}$ yuan $/ \mathrm{kWh}^{2}$; its rated power generation efficiency and heating efficiency are 0.36 and 0.54 , heat recovery and absorption refrigeration efficiency are 0.90 , gas boiler heating efficiency is 0.85 , and electrical energy efficiency coefficient is 3.30 The power generation efficiency and heating efficiency are 0.60 and 0.30 , respectively; the upper limit of the safe capacity for the operation of the hydrogen storage device is $500 \mathrm{Nm}^{3}$, and the hydrogen energy consumption is $3.37 \mathrm{~kW} / \mathrm{Nm}^{3}$. In addition, the price of natural gas is 3.58 yuan $/\left(\mathrm{m}^{3}\right)$, and the Table.2 Upper and lower limits of output of each device:

\begin{tabular}{|c|c|c|}
\hline & $\min$ & $\max$ \\
\hline$G T$ & 200 & 1000 \\
\hline grid & 500 & 3000 \\
\hline$E S_{\text {char }}$ & 100 & 300 \\
\hline$E S_{\text {dis }}$ & 100 & 200 \\
\hline$E C$ & 100 & 1000 \\
\hline$A C$ & 100 & 1000 \\
\hline$P_{\text {WTwaste }}$ & 0 & 2000 \\
\hline
\end{tabular}

Table.3 Upper and lower limits of each device in thermal load balancing:

\begin{tabular}{cccc}
\hline & $E S_{\text {char }}$ & $E S_{\text {dis }}$ & $G B$ \\
\hline $\min$ & 100 & 100 & 100 \\
$\max$ & 300 & 200 & 1500 \\
\hline
\end{tabular}

Table.4 Unit operation and maintenance costs of each device:

\begin{tabular}{|c|c|}
\hline$G T$ & 0.0063 \\
\hline$E S$ & 0.0832 \\
\hline$H S$ & 0.0450 \\
\hline$G B$ & 0.030 \\
\hline$H C$ & 0.0008 \\
\hline$A C$ & 0.0097 \\
\hline$E B$ & 0.0054 \\
\hline$F C$ & 0.0245 \\
\hline
\end{tabular}

calorific value of natural gas is $9.70 \mathrm{kWh} / \mathrm{m}^{3}$. The valley value, average value and peak value of the electricity price are 0.325 yuan / $\mathrm{kWh}, 0.857$ yuan / $\mathrm{kWh}$, and 1.378 yuan / $\mathrm{kWh}$ respectively. In the simulation stage, this paper divides the scheduling cycle into 24 periods and time interval is $\Delta t=1 \mathrm{~h}$. CPLEX, a commercial solver based on MATLAB, is used to solve the mixed integer nonlinear programming model established in this paper.

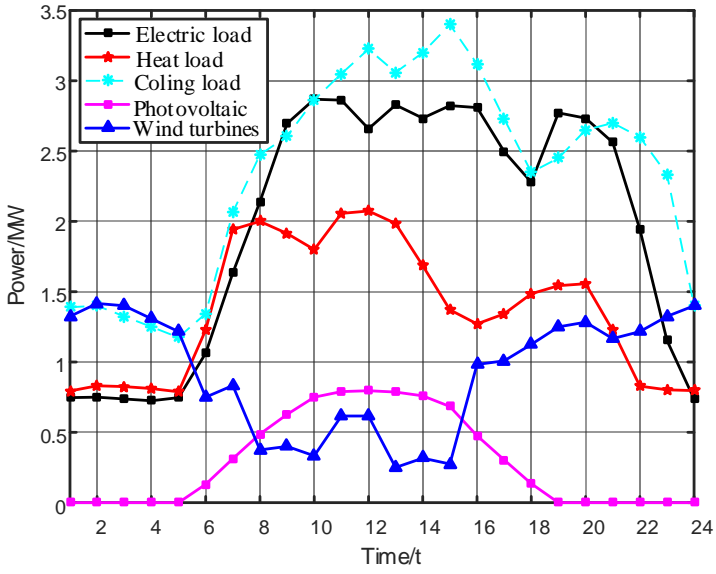

Fig.3 Estimated output of each load of the integrated energy system

It can be seen from Figure. 3 that the demand for electrical loads in each period shows a clear peak-to-valley change trend. The uncertainty of the output of a wind turbine appears during the peak period of its power in the periods 0-6 and 18-24. The electrical load is significantly reduced, and the wind turbine is overpowered. These two periods of time are the main working hours for electricity to produce hydrogen. The change trend of the thermal load is basically consistent with the electrical load. During the peak period of the load, the generated hydrogen can be supplied by the fuel cell device to the electrical load and the thermal load in the system to improve the energy utilization rate.

\section{B. Analysis of Integrated Energy System}

Comparative analysis of the impact of starting the hydrogen production unit-fuel cell unit on the integrated energy system under four scenarios.

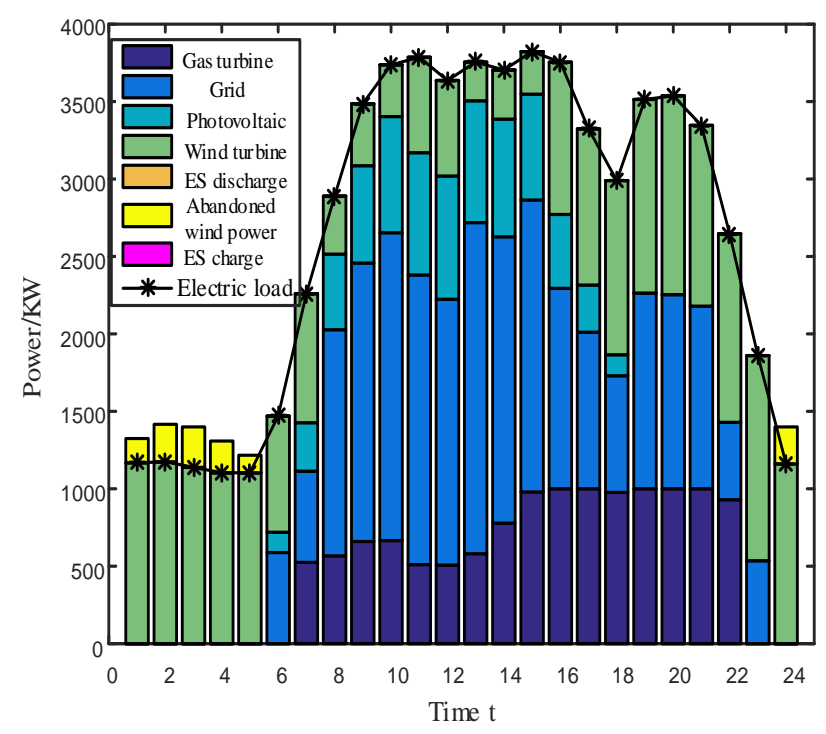

(a) 


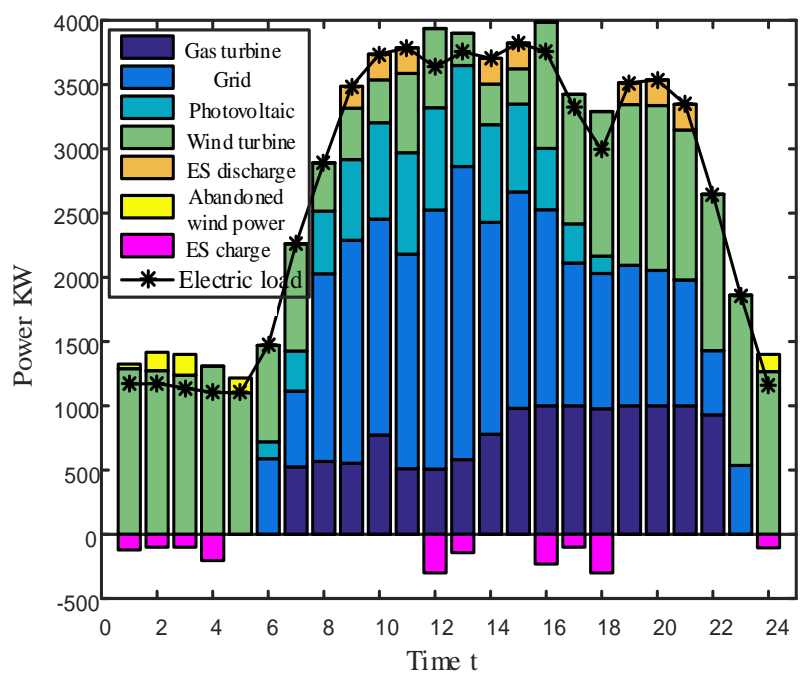

(b)

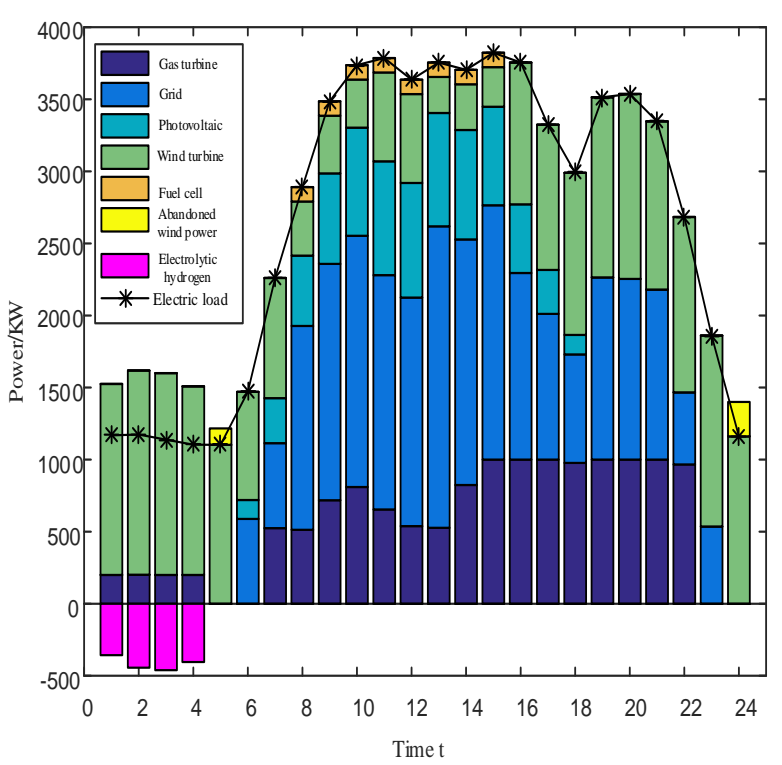

(c)

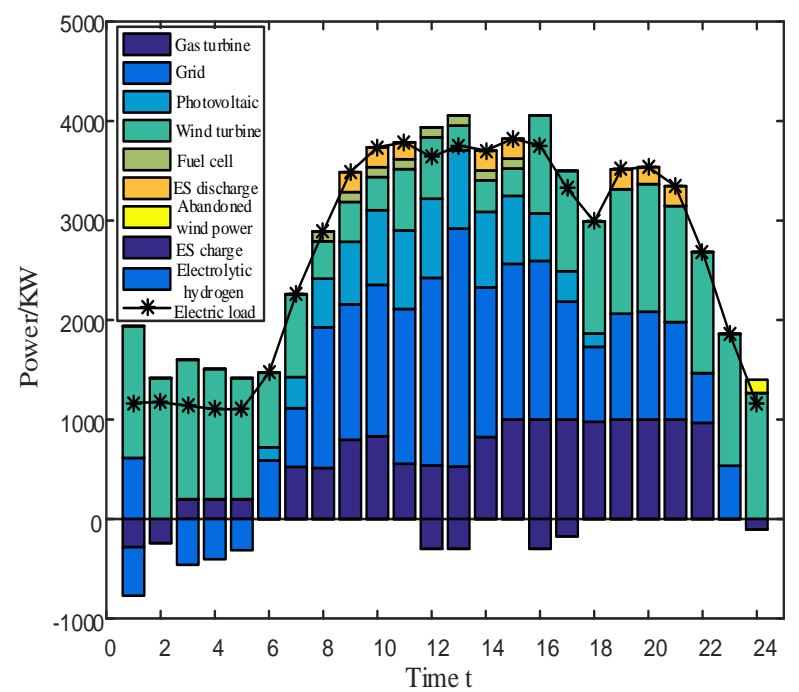

(d)

Fig.4 Operational comparison of electric power in different scenarios
Fig.4 shows the comparison of electrical load in different scenarios. The amount of wind power discarded in the integrated energy system that starts the electric hydrogen-fuel cell device is significantly reduced, and idle wind power is converted to hydrogen energy when wind power is left. The fuel cell supplies the electrical load in the system, reducing exchange with the external power grid. Fig.5 shows the comparison of the heat load in different scenarios. The fuel cell can also provide a certain amount of heat load in the system. Combining analysis with Fig. 4 and Fig.5, the electric hydrogen-fuel cell device has a significant impact on wind power consumption. During the operation of the fuel in the fuel cell, on the one hand, it can generate electric energy to meet the demand of the power load, and on the other hand, the thermal energy generated during the operation of the fuel cell can supply the heat load, thereby achieving the maximum utilization of resources.

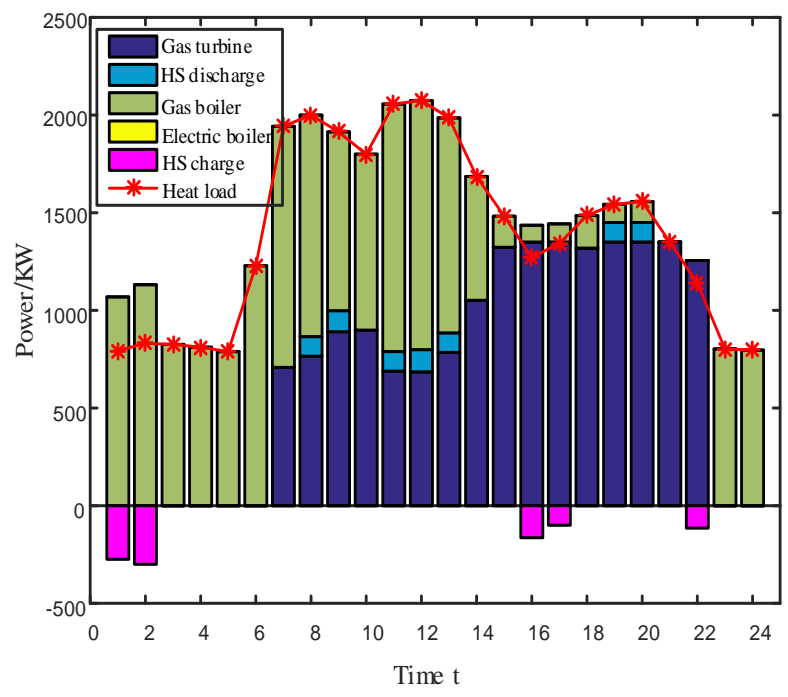

(a)

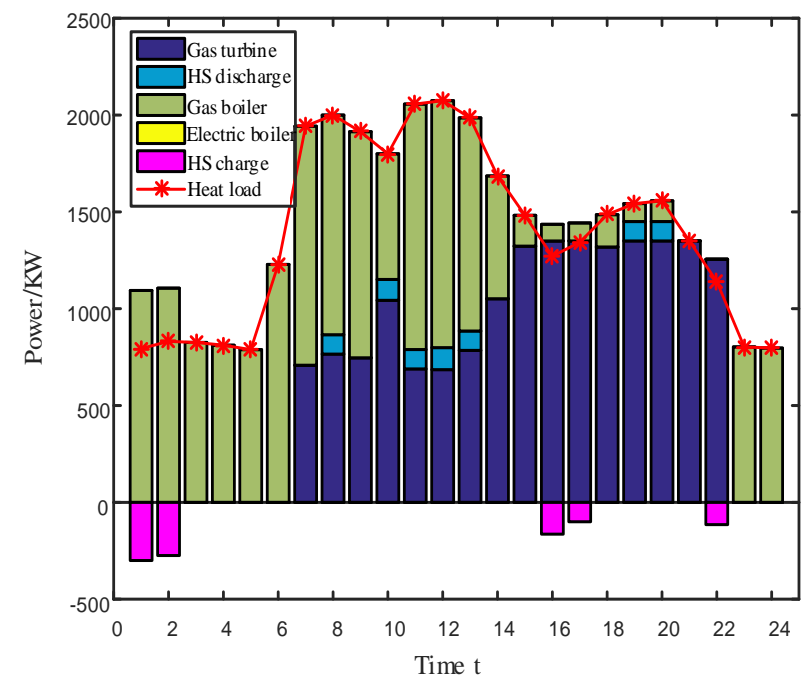

(b) 


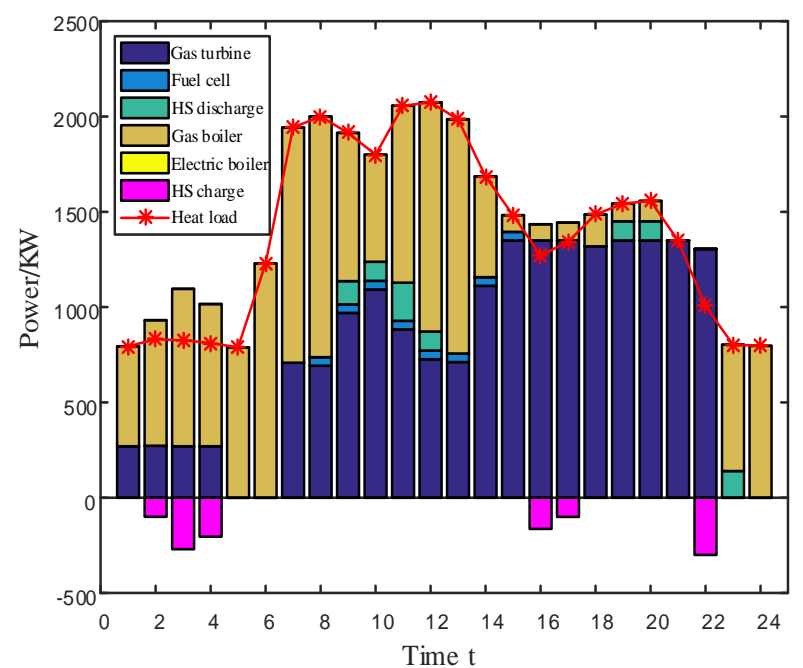

(c)

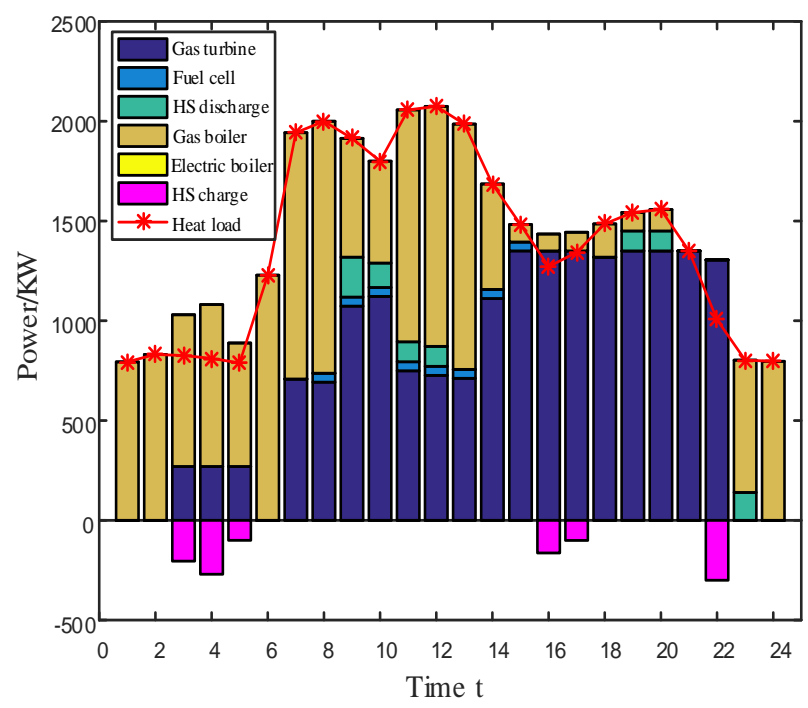

Fig.5 Operation of thermal load in different scenarios

After calculation, the comparison of wind power abandonment rate in different scenarios is shown in the table 5.

\begin{tabular}{ccccc}
\multicolumn{4}{c}{ Table.5 Comparison of abandonment rate in different scenarios : } \\
\hline Scenario 1 & Scenario 2 & Scenario 3 & Scenario 4 \\
\hline rate & $5.48 \%$ & $2.64 \%$ & $1.59 \%$ & $0.6 \%$ \\
\hline
\end{tabular}

It can be seen in the comparison that in a comprehensive energy system including an electric hydrogen-fuel cell device, the wind power abandonment rate is reduced and wind power consumption is promoted.

Table. 6 shows the operating costs of the system and the amount of wind abandoned in different scenarios. It can be seen that under the conditions of scenario 4, when the electric hydrogen-fuel cell device and electric energy storage are working at the same time, the operating cost of the integrated energy system is at least 45647.9 yuan, and the total abandoned wind power of the wind power is also at
Table.6 Comparison of operating results of integrated energy systems in different scenarios

\begin{tabular}{ccc}
\hline Scenario & $\begin{array}{c}\text { Total system operation cost / } \\
\text { yuan }\end{array}$ & $\begin{array}{c}\text { Total abandoned wind } \\
\text { power / kW }\end{array}$ \\
\hline 1 & 47634.1 & 1216.9 \\
2 & 46703.2 & 585.3 \\
3 & 46459.4 & 352 \\
4 & 45647.9 & 133 \\
\hline
\end{tabular}

least $133 \mathrm{KW}$; in the scenario Under the condition of 1 , the idle wind volume of the wind turbine is directly discarded, and the energy storage device is not started, and there is a great waste of energy use. At this time, the operating cost of the integrated energy system is up to 4,7634.1 yuan, and the total abandoned wind power of the wind power is the largest It is $1216.9 \mathrm{KW}$. Therefore, when the output of the fan is sufficient, proper use of the energy conversion device can obtain better economic benefits and promote the consumption of new energy sources, reduce the emission of carbon-containing gases, and improve the overall efficiency of the system.

\section{CONCLUSIONS}

This paper considers the use of the remaining output of wind turbines in an integrated energy system. Through the application of energy conversion devices, based on different uses of renewable energy sources, an integrated energy system optimization model for hydrogen-containing devices is proposed. The mutual conversion of these energy sources can simultaneously meet the electricity, heat, and cold load requirements in the system. The simulation results verify the effectiveness of the proposed model, and analyzes the important role of wind power hydrogen production equipment in reducing system operating costs and increasing clean energy consumption. The system operation conditions under different control modes are compared and reasonable arrangements are made. The use of wind turbine loads is conducive to further promoting the green and economic operation of the system.

1) Compared with the traditional integrated energy system, the integrated energy system containing wind power for hydrogen production mentioned in this article can use electric hydrogen production equipment to convert electrical energy to hydrogen energy, which is conducive to improving the dissipation of surplus wind power and improving energy efficiency. usage efficiency. 
2) Comparing the operating results of different utilization methods in the integrated energy system, it can be seen that rationally arranging the energy flow of the remaining renewable energy reduces the operating cost of the system and is conducive to further promoting the green and economic operation of the integrated energy system.

\section{REFERENCES}

[1] M.D.A. Al-Falahi, S.D.G. Jayasinghe, H. Enshaei, (2017). "A review on recent size optimization methodologies for standalone solar and wind hybrid renewable energy system," Energy Conversion and Management , 143, 252-274. Submitted for publication.

[2] A.L. Bukar, C.W. Tan, (2019). "A review on stand-alone photovoltaic-wind energy system with fuel cell: System optimization and energy management strategy,"Journal of Cleaner Production , 221, 73-88. Submitted for publication.

[3] A. Ahadi, S.-K. Kang, J.-H. Lee, (2016). "A novel approach for optimal combinations of wind, PV, and energy storage system in diesel-free isolated communities," Applied Energy , 170, 101-115. Submitted for publication.

[4] R. Dufo-Lopez, J.L. Bernal-Agustin, (2007). "J. Contreras, Optimization of control strategies for stand-alone renewable energy systems with hydrogen storage," Renewable Energy , 32,1102-1126. Submitted for publication.

[5] M.K. K. Agbossou, J. Hamelin ,T.K. Bose, (2004). "Performance of a stand-alone renewable energy system based on energy storage as hydrogen," IEEE Transactions on Energy Conversion, 19, 633 - 640. Submitted for publication.

[6] G. Giannakoudis, A.I. Papadopoulos, P. Seferlis, S. Voutetakis, (2010). "Optimum design and operation under uncertainty of power systems using renewable energy sources and hydrogen storage,", 35, 872-891. Submitted for publication.

[7] M.S. Ismail, M. Moghavvemi, T.M.I. Mahlia, K.M. Muttaqi, S. Moghavvemi, (2015). "Effective utilization of excess energy in standalone hybrid renewable energy systems for improving comfort ability and reducing cost of energy: A review and analysis," Renewable \& Sustainable Energy Reviews, 42, 726-734. Submitted for publication.

[8] G. Cau, D. Cocco, M. Petrollese, S.K. Kaer, C. Milan, (2014), "Energy management strategy based on short-term generation scheduling for a renewable microgrid using a hydrogen storage system," ENERGY CONVERSION AND MANAGEMENT , 87, 820-831. Submitted for publication.

[9] F.J. Vivas, A. De las Heras, F. Segura, J.M. Andujar, (2018). “A review of energy management strategies for renewable hybrid energy systems with hydrogen backup," RENEWABLE \& SUSTAINABLE ENERGY REVIEW, 82, 126-155. Submitted for publication.
[10] M. Castaneda, A. Cano, F. Jurado, H. Sanchez, L.M. Fernandez, (2013). "Sizing optimization, dynamic modeling and energy management strategies of a stand-alone PV/hydrogen/battery-based hybrid system," International Journal of Hydrogen Energy 38,3830-3845. Submitted for publication.

[11] J.J. Hwang, L.K. Lai, W. Wu, W.R. Chang, (2009) . "Dynamic modeling of a photovoltaic hydrogen fuel cell hybrid system,", 34, 9531-9542. Submitted for publication.

[12] C. Sanchez, B. Abad, S. Huebner, D. Alfonso, I. Segura, (2011) . "Wind park reliable energy production based on a hydrogen compensation system. Part I: Technical viability," International Journal of Hydrogen Energy ,36, 15548-15560. Submitted for publication

[13] L.M. Gandia, R. Oroz, A. Ursua, P. Sanchis, P.M. Dieguez, (2007) . "Renewable hydrogen production: Performance of an alkaline water electrolyzer working under emulated wind conditions," Energy \& Fuels ,21, 1699-1706. Submitted for publication.

[14] J. Ye, Yuan Rongxiang, (2018). "Stochastic scheduling of integrated electricity-heat-hydrogen systems considering power-to-hydrogen and wind power," Journal of Renewable and Sustainable Energy, 10. Submitted for publication.

[15] D. Huang, Qi, Deqing, Yu, Na, Cai Guowei, (2017). "Capacity Allocation Method Of Hydrogen Production System Consuming Abandoned Wind Power," Taiyangneng Xuebao , 1517-1525. Submitted for publication. 